\title{
A structural and cytochemical study of the effects of gossypol on the epithelial cells of the guinea-pig seminal vesicle
}

\author{
Y. C. Wong and C. C. Tam \\ Department of Anatomy, Faculty of Medicine, University of Hong Kong, Hong Kong
}

\begin{abstract}
Summary. Gossypol acetic acid, given to guinea-pigs at a concentration of $10 \mathrm{mg} / \mathrm{kg}$ daily for up to 7 weeks, exerted an inhibitory effect on the secretory activity of the glandular cells of the seminal vesicles. The diminished secretory function was associated with a decrease in thiamine pyrophosphatase (TPPase) (EC 3.6.1.6) activity in the luminal border and the Golgi cisternae. There was no increase in cytoplasmic filaments, and mitochondrial damage was not observed. The most striking effect was on the basal lamina, where the lamina densa increased significantly in thickness, while the lamina lucida decreased marginally in thickness. This was coupled with an increase in proteoglycan content on both sides of the lamina densa. It would appear that gossypol reduces the luminal secretory function on the one hand, while it increases the basal secretory activity on the other, thus modifying the structure of the basal lamina. The functional significance of these changes remains unknown.
\end{abstract}

Keywords: gossypol; seminal vesicle; guinea-pig; structure

\section{Introduction}

There has been a large number of publications on the use of gossypol for regulation of male fertility, contributing a major step in the search for a male contraceptive (Liu, 1957; Wang \& Lei, 1979; Wu \& Shi, 1979; Liu et al., 1981; Xue, 1981; Prasad \& Diczfalusy, 1983). More recent studies have demonstrated that gossypol also exhibits antifertility activity in male rodents, rabbits and monkeys (Xue, 1981; Hoffer, 1982, 1983; Prasad \& Diczfalusy, 1983; Xue et al., 1983). Most of the basic and clinical studies carried out in China and elsewhere have used gossypol or gossypol acetic acid. The resulting damage to the testes seems to be specific, affecting the spermatids at certain stages of development, and also mature spermatozoa (Dai et al., 1978; Hadley et al., 1981; Xue, 1981). On the other hand, very little work has been done on the effect of this drug on the male accessory sex glands. Earlier reports from China indicated that gossypol has no effect on the structure of and amount of those enzymes related to steroid hormone synthesis in the interstitial cells. Moreover, no change in the size, weight and morphology of the accessory sex glands or the concentration of testosterone was reported (Xue, 1981). In contrast to these reports, Wong \& Tam $(1983,1984,1985,1988)$ have reported that gossypol acetic acid has an inhibitory effect on the secretory activity of the seminal vesicle and the prostate, while others have reported that gossypol significantly reduces the blood testosterone concentration (Lin et al., 1981; Hahn et al., 1981; Liang et al., 1981). The present study was undertaken to examine the structural and cytochemical changes of the seminal vesicle after gossypol treatment. Thiamine pyrophosphatase (TPPase) (EC 3.6.1.6), a marker enzyme located in the Golgi, was chosen to monitor the Golgi activities of the cells after gossypol treatment. 


\section{Materials and Methods}

Five male guinea-pigs weighing $0.8-1.0 \mathrm{~kg}$ each, were kept in standard laboratory conditions of $14 \mathrm{~h} \mathrm{light} / 10 \mathrm{~h}$ dark. They were force fed with gossypol acetic acid in Tween -80 at a concentration of $10 \mathrm{mg} / \mathrm{kg}$ body weight daily for up to 7 weeks. Three control animals were kept under identical conditions and fed with the carrier alone.

Anaesthesia was induced by an intraperitoneal injection of an excess dose of pentobarbitone sodium. The animals were cannulated at the thoracic aorta, with the inferior vena cava cut. The vascular system was then flushed with $300 \mathrm{ml}$ heparinized saline. This was then followed by $500 \mathrm{ml}$ fixative containing $2 \mathrm{~mm}-\mathrm{MgCl}_{2}, 2 \cdot 5 \%$ glutaraldehyde and $2 \%$ paraformaldehyde in $0.1 \mathrm{M}$-cacodylate buffer at $\mathrm{pH} 7 \cdot 2$. After perfusion, the seminal vesicles were removed and fixed in the same fixative for a further $2-4 \mathrm{~h}$ at $4^{\circ} \mathrm{C}$, then post-fixed with $1 \%$ osmium tetroxide for $1-4 \mathrm{~h}$, dehydrated and embedded in Taab for transmission electron microscopy. At least 5 blocks from each animal were cut. Thin sections were stained with uranyl acetate and lead citrate and examined with a Philips EM 300 electron microscope.

For cytochemical demonstration of thiamine pyrophosphatase (TPPase) activity, tissue was cut with a tissue chopper to a thickness of 50-75 $\mathrm{m}$ immediately after perfusion. The sections were incubated for TPPase activity in a medium prepared according to the method of Novikoff \& Goldfischer (1961), using cocarboxylase as substrate for $2 \mathrm{~h}$, at $37^{\circ} \mathrm{C}$. Substrate omission in the incubating medium served as control for TPPase activity.

After incubation, the tissue was rinsed and post-fixed in $1 \%$ osmium tetroxide for $1 \mathrm{~h}$, and stained en bloc with uranyl acetate before embedding for examination by electron microscopy. No further staining was performed on these sections.

\section{Results}

\section{Morphological changes}

The fine structure of the guinea-pig seminal vesicles has been described by others (Veneziale et al., 1974; Tse \& Wong, 1980), and only those features pertinent to the present study will be given here. The epithelium consists of tall columnar cells resting on a smooth continuous basement membrane, separating the epithelium from the loose lamina propria which contains sparse collagen and cells. The epithelial cells are richly endowed with granular endoplasmic reticulum (GER), typical dense-cored secretory granules and a few short microvilli (Fig. 1).

Some cells appeared normal even after 7 weeks of treatment, while others underwent mild degrees of alteration. The Golgi apparatus appeared to be slightly smaller and many cells had fewer and smaller secretory granules (Figs $2 \& 3$ ). Despite the decrease in size, the secretory granules retained their normal dense-cored appearance. Clear granules, which are a prominent feature seen in the prostate gland of similarly-treated guinea-pigs (Wong \& Tam, 1988), were not observed in the seminal vesicles.

The GER profiles appeared less well organized and were less compactly arranged. There was no concurrent increase in filamentous content and the mitochondria appeared unaffected in the seminal vesicle (Fig. 3). There was, however, an increase in lipid content in the cells, as lipoid globules were more frequently found (Fig. 4).

Marked changes were observed in the epithelial-stromal junction, however. In the normal untreated seminal vesicle, the relatively smooth basal lamina separating the epithelia from the

Fig. 1. Electron micrograph showing the apical portion of epithelial cells of the seminal vesicle from a control animal. Note the typical dense cored secretory granules (SG), and well developed GER $\times 29540 ;$ bar $=1 \mu \mathrm{m}$.

Fig. 2. The secretory granules of the epithelial cells decrease in number and size 7 weeks after gossypol treatment. The Golgi $(G)$ also decreases in size, but the changes in GER in these cells are not very distinctive. Note also that the mitochondria $(\mathbf{M})$ appear normal. $\times 18200$; bar $=$ $1 \mu \mathrm{m}$.

Fig. 3. Micrograph showing the small Golgi with forming granules (arrows). $\times 24760$; bar $=1 \mu \mathrm{m}$. 

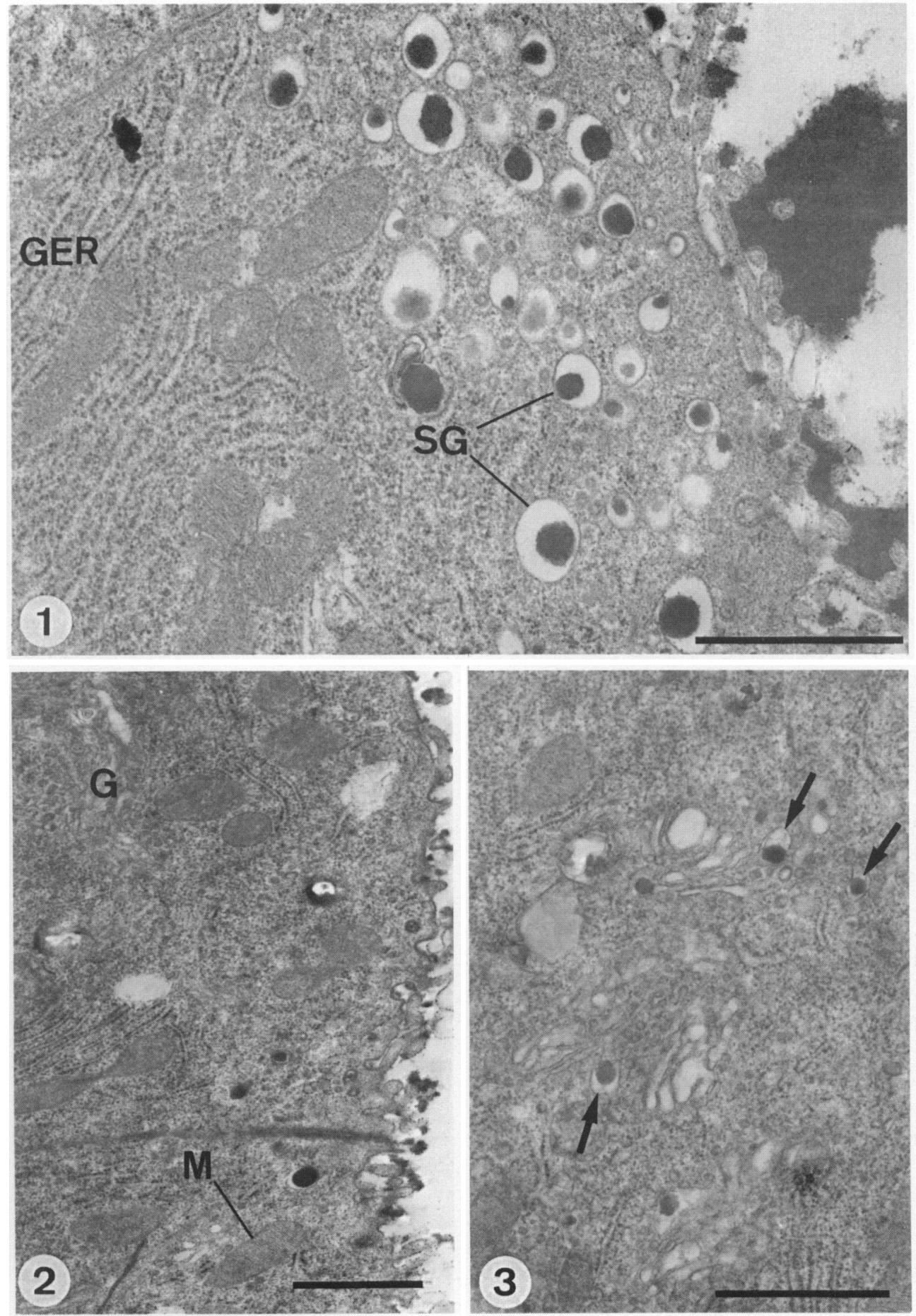

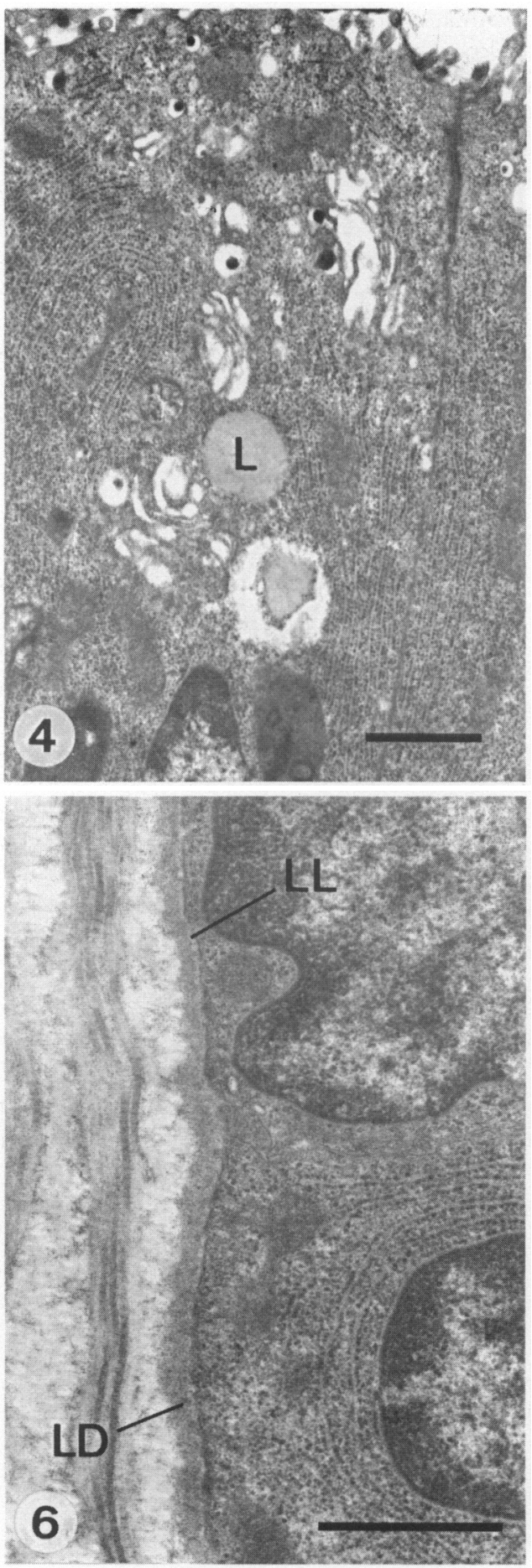
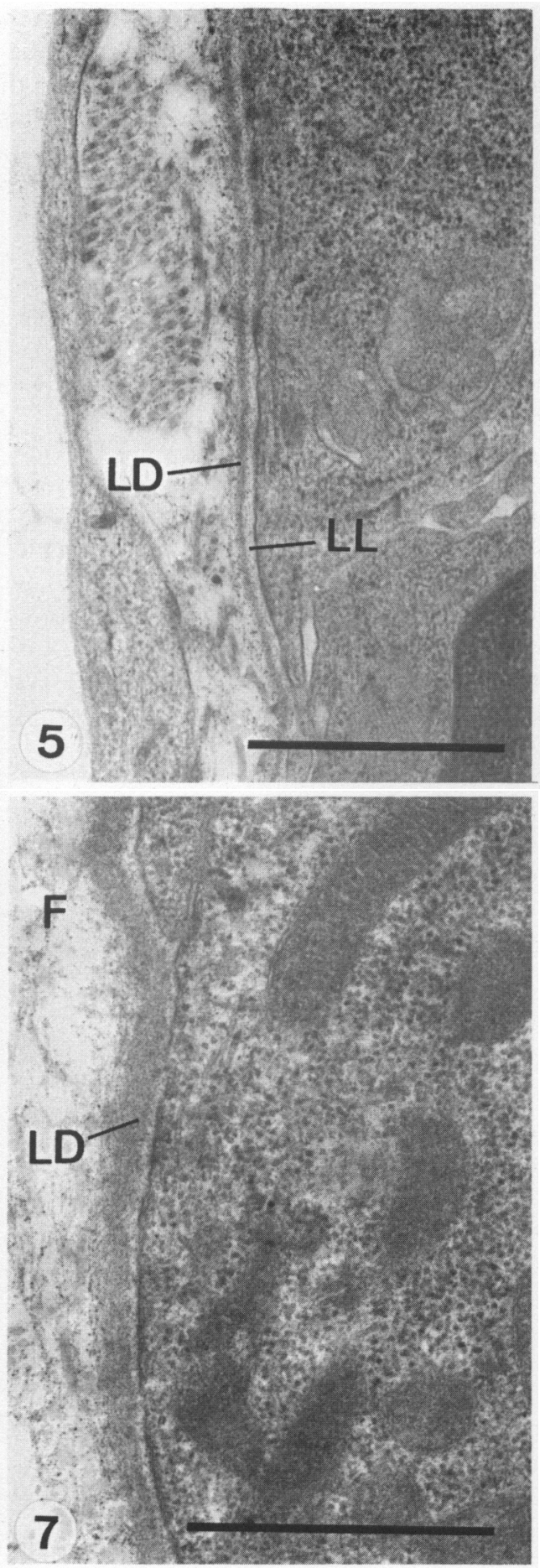
stromal tissue measured about $80 \mathrm{~nm}$ in thickness (Fig. 5). It is divided more or less equally between the lamina densa (an electron-dense layer) and the lamina lucida (an electron-translucent layer). In gossypol-treated animals, patchy changes in the thickness and structure of the basal lamina were observed. The lamina densa often increased in thickness to $120-180 \mathrm{~nm}$ compared to about $40 \mathrm{~nm}$ in the control, while the lamina lucida often became less distinctive, ranging from 10 to $30 \mathrm{~nm}$ (Figs $6 \& 7$ ). In some sections, a fine filamentous network was seen extending from the stromal surface of the lamina densa (Fig. 7). In some tissues, after prolonged fixation in osmic acid, regularly spaced dense granules were found associated with both sides of the lamina densa (Fig. 8). These granules are believed to be proteoglycans made visible by osmic acid fixation (Revel \& Hay, 1963; Hay, 1981). Granules present on the epithelial side were of $30 \mathrm{~nm}$ in diameter, while those on the stromal side were about $50 \mathrm{~nm}$. In places these granules were closely packed on the surface of the lamina densa so as to form a continuous layer (Fig. 9). This is in contrast to the normal untreated animals in which they are regularly spaced at intervals of $60 \mathrm{~nm}$ (unpublished observation).

\section{TPPase activities}

Normal controls. In the normal vesicle, the reaction products were found in $2-3$ trans-Golgi cisternae (Fig. 10). The reaction was intense, and the reactive products completely filled the lumen of the cisternae concerned. Other sites of positive activity were found in the luminal (Fig. 11) and lateral cell membranes (Figs 10,12), and in some lysosomes (Fig. 13). Reactive products were also observed in some secretory granules (Fig. 11), mainly restricted to the periphery of the granules.

Gossypol-treated animals. In these guinea-pigs, TPPase activity was persistently found to be less than that in the normal controls. Only sparse patchy deposition of reactive products was found in the Golgi, luminal and lateral borders (Figs $14 \& 15$ ). The lateral borders often showed minimal (Fig. 14) or no activity. TPPase activity in lysosomes was also reduced, and very few lysosomes showed a positive reaction (Figs $15 \& 16$ ). Occasional secretory granules were found with scanty TPPase deposition. Because of the difficulties in quantifying the cytochemical results, care was taken to ensure that only sections from superficial tissue of the blocks were examined to avoid any possible differences in reactivity of the enzyme which might have arisen from a difference in distance of substrate diffusion.

\section{Discussion}

The results of the present investigation confirm our earlier studies that gossypol depresses the secretory activity of the male accessory sex glands including the prostate gland (Wong \& Tam, 1988). This is reflected in the reduction in size of the Golgi apparatus and the number of secretory

Fig. 4. Micrograph showing an increase in lipid (L) content after gossypol treatment. $\times 13975$; bar $=1 \mu \mathrm{m}$.

Fig. 5. Micrograph of the epithelial-stromal interface showing the basal lamina of cells from a control animal. Note the typical basal lamina $(\sim 80 \mathrm{~nm})$ with roughly equal thickness of lamina densa (LD) and lamina lucida (LL). $\times 30650$; bar $=1 \mu \mathrm{m}$.

Fig. 6. The micrograph shows the basal lamina from a treated animal. The lamina densa (LD) greatly increases in thickness $(120 \mathrm{~nm})$ while the lamina lucida (LL) decreases to $10-30 \mathrm{~nm}$. $\times 21730$; bar $=1 \mu \mathrm{m}$.

Fig. 7. Micrograph showing the tremendous increase in thickness in the lamina densa $(150 \mathrm{~nm})$. A fine filamentous (F) network can be traced from the stromal surface of the lamina densa and merges with the underlying connective tissue. $\times 36580$; bar $=1 \mu \mathrm{m}$. 

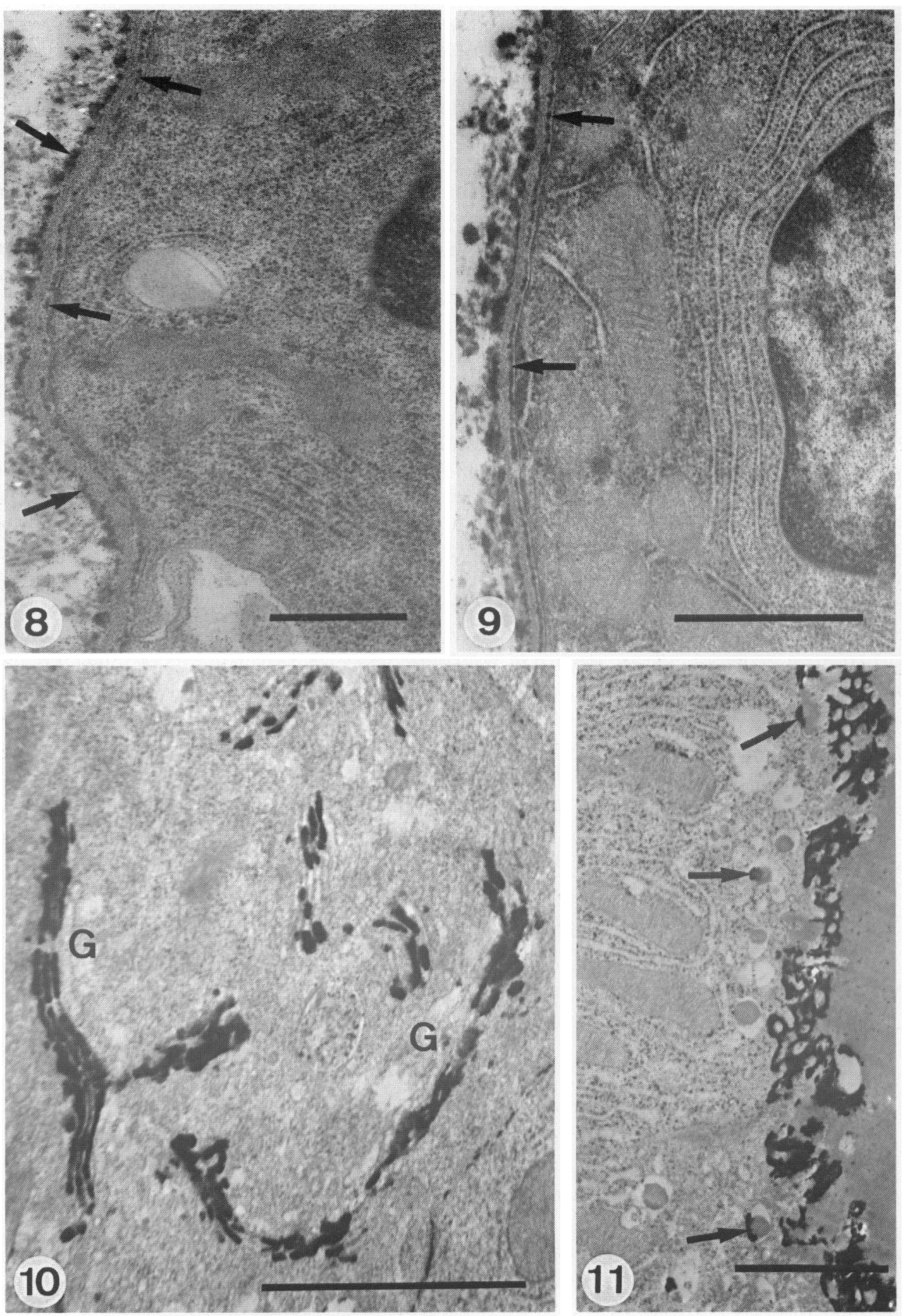
granules. The mechanism is unknown. It has been reported in several animal species that gossypol affects serum androgen concentrations (Hahn et al., 1981; Liang et al., 1981; Donaldson et al., 1985). It would seem likely that perturbation of endocrine function might also occur in the guineapig, and that the structural changes observed in the seminal vesicle may be secondary to the altered hormonal levels.

TPPase is an enzyme located in several trans-cisternae and works in concert with galactosyltransferase to allow transfer of galactose to glycoprotein in the Golgi apparatus. TPPase catalyses the reaction to convert uridine diphosphate (UDP) to uridine monophosphate (UMP) and inorganic phosphate. The function of TPPase is, therefore, to avoid accumulation of UDP, thus preventing the inhibition of galactosyltransferase activity by UDP. TPPase activity therefore reflects the traffic through the Golgi cisternae and, hence, the secretory activity of the cells (Roth \& Berger, 1982). The presence of TPPase-reactive products in the luminal and lateral borders is puzzling. TPPase activity has been reported to be present in selected regions of the cell membrane (Castel \& Dellman, 1980; Laszlo \& Bodor, 1981) other than the Golgi. The observation of TPPase reactive products in the membrane of some secretory granules indicates a possible link between the Golgi and TPPase of the luminal membrane. By the same token, the presence of TPPase reactive products in the lysosomes may also indicate their origin from the Golgi cisternae.

After gossypol treatment, the secretory granules not only became smaller in size, but also in number. Their morphology, however, remained similar to that of the control animals, i.e. a dense core surrounded by a loosely-fitted membrane. Wong \& Tam (1988) reported that gossypol modifies the secretory granules in guinea-pig prostate gland, resulting in the formation of a second type of 'clear granule' in the lateral and dorsal lobes. Similar 'clear granules' were, however, not found in the present study of the seminal vesicles.

On the other hand, gossypol has been shown to cause damage to mitochondria in a number of tissues (Xue, 1981; Hoffer, 1982, 1983; Oko \& Hrudka, 1982; Tanphaichitr et al., 1984; Hu et al., 1986; Robinson et al., 1986), including the dorsal prostate and the coagulating gland of the guineapig (Wong \& Tam, 1988). However, similar damage was not observed in the seminal vesicles. This confirms again that there might be differences in susceptibility in mitochondrial damage by gossypol. For the accessory sex glands of the guinea-pig, mitochondria of both the lateral prostate (Wong \& Tam, 1988) and the seminal vesicle are more resistant to gossypol while the dorsal lobe of the prostate and the coagulating gland, like other tissues, are more susceptible to gossypol damage (Xue, 1981; Hoffer, 1982; Eliasson \& Virji, 1983).

The most striking changes in the seminal vesicle after gossypol treatment appear to be in the basal lamina (Figs 6, 7, 8 \& 9). There was a dramatic increase in thickness of the basal lamina from about $80 \mathrm{~nm}$ in the normal control to about $200 \mathrm{~nm}$ after gossypol treatment. The increase was

Fig. 8. This micrograph shows in addition to the greatly increased basal lamina $(\sim 180 \mathrm{~nm})$, dense granules on both sides of the lamina densa (arrows). The granules in the lamina lucida measure about $30 \mathrm{~nm}$ while those on the outer side of the lamina densa are about $50 \mathrm{~nm}$. These granules are believed to be the proteoglycans, made visible by prolonged fixation in osmic acid. $\times 29170$; bar $=1 \mu \mathrm{m}$.

Fig. 9. This micrograph shows the dense granules on both sides of the lamina densa forming a continuous layer (arrows). Note also the layer of granules on the stromal surface of the lamina densa. $\times 26580$; bar $=1 \mu \mathrm{m}$.

Fig. 10. Epithelial cells showing the distibution of the TPPase reactive products in the control animal. Note that the enzyme is concentrated mainly in the Golgi $(G)$, where the dense products fill completely the 2-3 trans cisternae. $\times 37300$; bar $=1 \mu \mathrm{m}$.

Fig. 11. Micrograph showing the reactive products in the apical border in a control animal. Several secretory granules (arrows) also show positive activity. $\times 21350 ; \mathrm{bar}=1 \mu \mathrm{m}$. 

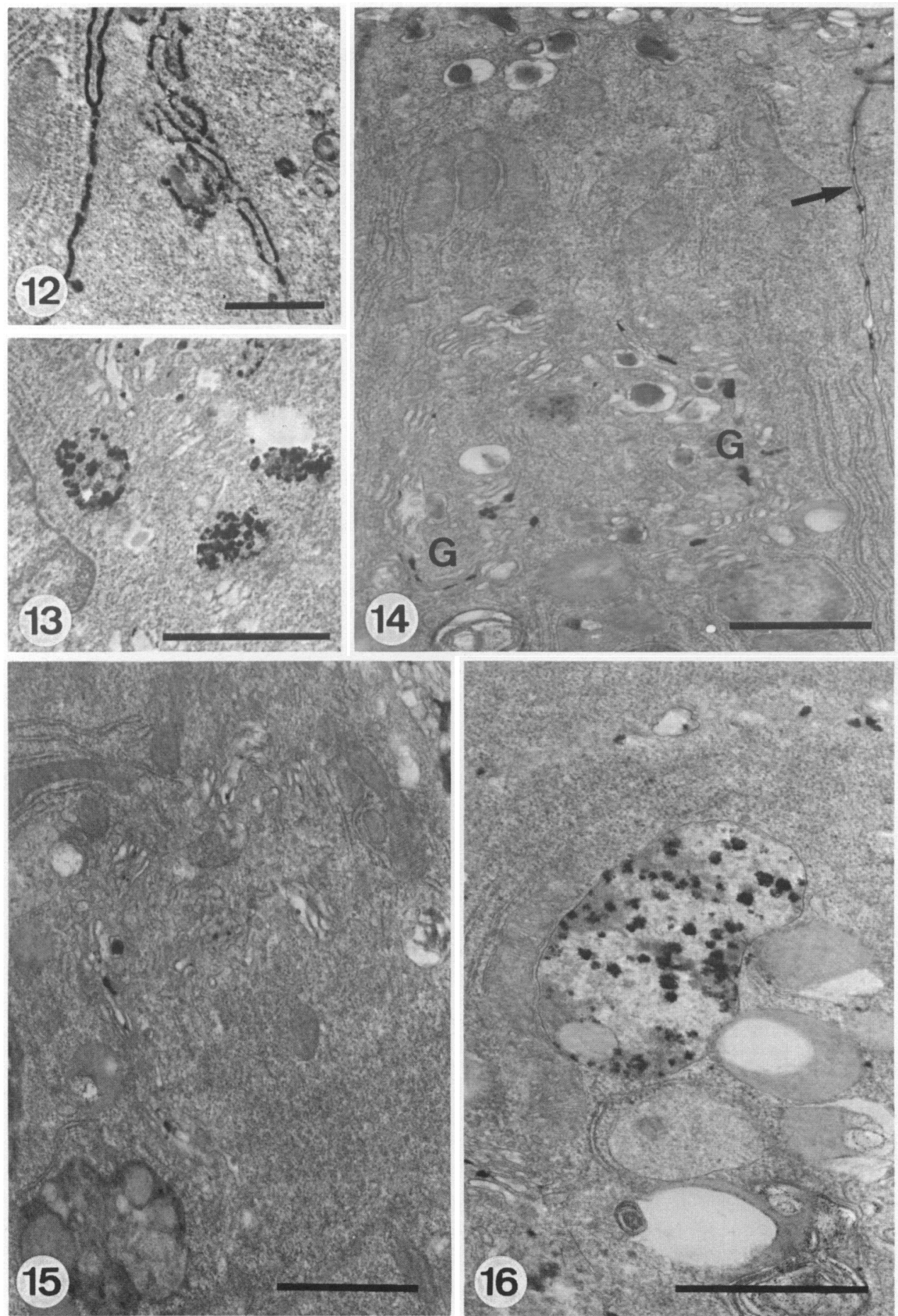
Fig. 12. Micrograph showing the presence of reactive products along the lateral membrane in a control animal. $\times 27760$; bar $=0.5 \mu \mathrm{m}$.

Fig. 13. Micrograph showing three lysosomes positively reacting with TPPase activity in a control animal. $\times 23290$; bar $=1 \mu \mathrm{m}$.

Fig. 14. Micrograph showing the supranuclear cytoplasm of the cell. The TPPase reactive products become greatly reduced in the gossypol-treated animal. The reactive products become patchy in Golgi $(G)$, the luminal and also the lateral borders (arrows). $\times 19430$; bar $=1 \mu \mathrm{m}$.

Fig. 15. Micrograph showing minimal TPPase activities in the Golgi but negative in a secondary lysosome (lower left). $\times 19700$; bar $=1 \mu \mathrm{m}$.

Fig. 16. Several lysosome-like structures are shown, but only one shows enzyme activities. $\times 26800$; bar $=1 \mu \mathrm{m}$.

mainly in the lamina densa where it increased from the normal $40 \mathrm{~nm}$ to as much as $180 \mathrm{~nm}$. The lamina lucida, on the other hand, became slightly thinner $(10-30 \mathrm{~nm}$ compared to $40 \mathrm{~nm}$ in the normal control). However, these changes in the basal lamina were not uniform: relatively standard thickness was observed in some regions while in others the lamina densa was variously increased to $120-180 \mathrm{~nm}$. The effects of gossypol on the basal lamina has not been reported before, and the significance of such changes to the epithelial cells is not known.

In the kidney, the glomerulus has a greatly thickened basal lamina where it serves, among other functions, as a filtration barrier. Basal lamina thickening is a prominent feature in diabetes (Osterby, 1980; Rohrbach et al., 1982; Martinez-Hernandez \& Amenta, 1983), which may alter the function of the basal lamina, resulting in development of the nephrotic syndrome (MartinezHernandez \& Amenta, 1983). The exact reason for basal lamina thickening in our present study is not known. There seemed to be an increase in density of proteoglycan granules in the thickened basal lamina, at times to the point of forming a continuous layer on both sides of the lamina densa (Fig. 9). The increase in proteoglycans is accompanied by an increase in thickness of lamina densa (presumably resulting from increased synthesis of type IV collagen and laminin). This indicates that, under the effect of gossypol, synthesis of both proteoglycans and type IV collagen is also increased. If this interpretation is correct, then gossypol appears to depress the secretory activity of the epithelial cells at the luminal border, but raise the secretory activity along the basal border, resulting in thickening of the basal lamina.

We thank Miss Helen Li for technical assistance and Mr Johnny Leung for photography.

\section{References}

Castel, M. \& Dellman, H.D. (1980) Thiamine pyrophosphatase activity in the axonal smooth endoplasmic reticulum of neurosecretory neurons. Cell Tiss. Res. 210, 205-221.

Dai, R.X., Pang, S.N., Lin, X.K., Ke, Y.B., Liu, Z.L. \& Dong, R.H. (1978) A study of antifertility of cottonseed. Acta biol. exp. Sin. 11, 1-14.

Donaldson, A., Sufi, S.B. \& Jeficoate, S.L. (1985) Inhibition by gossypol of testosterone production by mouse Leydig cells in vitro. Contraception 31, 165-171.

Eliasson, R. \& Virji, N. (1983) Effects of gossypol acetic acid on the activity of LDH-C from human and rabbit spermatozoa. Int. J. Androl. 6, 109-112.

Hadley, M.A., Liu, C.Y. \& Dym, M. (1981) Effects of gossypol on the reproductive system of male rats. $J$. Androl. 2, 190-199.
Hahn, D.W., Resticus, C., Probst, A., Homm, R. \& Johnson, A.N. (1981) Antifertility and endocrine activities of gossypol in rodents. Contraception 24, 97-105.

Hay, E.D. (1981) Extracellular matrix. J. Cell Biol. 91, $205 \mathrm{~s}-223 \mathrm{~s}$.

Hoffer, A.P. (1982) Ultrastructural studies of spermatozoa and the epithelial lining of the epididymis and vas deferens in rats treated with gossypol. Archs Androl. 8, 223-246.

Hoffer, A.P. (1983) Effects of gossypol on the seminiferous epithelium in the rat: a light and electron microscope study. Biol. Reprod. 28, 1007-1020.

Hu, F.N., Mah, K.N. \& Teramura, D.H. (1986) Gossypol effects on cultured normal and malignant melanocytes. In vitro Cell. Devl Biol. 22, 583-588. 
Laszlo, I. \& Bodor, T. (1981) Localization of thiamine pyrophosphatase activity in motor end plates. $J$. Histochem. Cytochem. 29, 658-662.

Liang, S.X., Pang, S.N., Dong, R.N. \& Dai, R.X. (1981) Radioimmunoassay of serum concentrations of testosterone and $\mathbf{L H}$ in male rats administered with gossypol. Acta biol. exp. Sin. 2, 191-197.

Lin, T., Murano, E.P., Ostermum, J., Nankin, H.R. \& Coulson, P.B. (1981) Gossypol inhibits testicular steroidogenesis. Fert. Steril. 35, 563-566.

Liu, B.S. (1957) Suggestions of feeding crude cottonseed oil for contraception. Shanghai Acta Medica 6, 43. 47.

Liu, Z.Q., Liu, G.Z., Hei, L.S., Zhang, R.A. \& Yu, C.Z. (1981) Clinical trial of gossypol as a male antifertility agent. In Recent Advances in Fertility Regulation, pp. 160-163. Eds C. F. Chang, D. Griffin \& A. Woolman. S.A. Atar Press, Geneva.

Martinez-Hernandez, A. \& Amenta, P.S. (1983) The basement membrane in pathology. Lab. Invest. 48, 656677.

Novikoff, A.B. \& Goldfischer, S. (1961) Nucleosidediphosphatase activity in the Golgi apparatus and its usefulness for cytological studies. Proc. nat. Acad. Sci. U.S.A. 47, 802-810.

Oko, R. \& Hrudka, F. (1982) Effect of gossypol on spermatozoa. Archs Androl. 9, 39-40.

Osterby, R. (1980) Basement membrane morphology in diabetes mellitus. In Secondary Diabetes: the Spectrum of the Diabetic Syndromes, p. 47. Eds S. Padolsky \& M. Viswanathan. Raven Press, New York.

Prasad, M.R.N. \& Diczfalusy, E. (1983) Gossypol. In Endocrine Mechanisms in Fertility Regulation, pp. 233-248. Eds G. Benagiano \& E. Diczfalusy. Raven Press, New York.

Revel, J.P. \& Hay, E.D. (1963) An autoradiographic and electron microscopic study of collagen synthesis in differentiating cartilage. Z. Zellforsch. mikrosk, Anat. 61, 110-144.

Robinson, J.M., Tanphaichitr, N. \& Bellve, A.R. (1986) Gossypol-induced damage to mitochondria of transformed Sertoli cells. Am. J. Path. 125, 484-492.

Rohrbach, D.H., Hassell, J.R., Kleinman, H.K. \& Martin, G.R. (1982) Alterations in basement membrane (heparan sulfate) proteoglycans in diabetic mice. Diabetes 31, 185-188.
Roth, J. \& Berger, E.G. (1982) Immunocytochemical localization of galactosyltransferase in HeLa cells: codistribution with thiamine pyrophosphatase in trans-Golgi cisternae. J. Cell Biol. 92, 223-229.

Tanphaichitr, N., Chen, L.B. \& Bellve, A.R. (1984). Direct effect of gossypol on TR-ST cells: perturbation of rhodamine 123 accumulation in mitochondria. Biol. Reprod. 31, 1049-1060.

Tse, M.K.W. \& Wong, Y.C. (1980) Structural study of the involution of the seminal vesicles of the guinea pig following orchiectomy. Acta Anat. 108, 68-78.

Veneziale, C.M., Brown, A.L. \& Prendergast, F.G. (1974) Histology and fine structure of guinea pig seminal vesicle. Mayo clin. Proc. 449, 309-313.

Wang, N.G. \& Lei, H.P. (1979) Antifertility effect of gossypol acetic acid on male rats. Nat. Med.J. Chin. 59, $402-405$.

Wong, Y.C. \& Tam, C.C. (1983) Effect of gossypol acetic acid on the prostate gland of the guinea pig. Anat. Rec. 205, 219 a.

Wong, Y.C. \& Tam, C.C. (1984) Effect of gossypol acetic acid on thiamine pyrophosphatase activity of the guinea pig seminal vesicles. Proc. 3 rd Int. Congr. Cell Biol., Tokyo, p. 1250, abstr.

Wong, Y.C. \& Tam, C.C. (1985) Fine structural and cytochemical studies of seminal vesicles of the guinea pig after treatment with gossypol. Proc. 11th Int. Anat. Congr. London, p. 784, Abstr.

Wong, Y.C. \& Tam, C.C. (1988) Effect of gossypol on the prostate gland of the guinea pig. An ultrastructural study. Acta Anat. In Press.

Wu, X.R. \& Shi, Z.A. (1979) Gossypol-a new contraceptive for male. Acta Acad. Med. Wuhan 1, 102-105.

Xue, S.P. (1981) Studies on the antifertility effect of gossypol, a new contraceptive for males. In Recent Advances in Fertility Regulation, pp. 122-147. Eds C. F. Chang, D. Griffin \& A. Woolman. S.A. Atar Press, Geneva.

Xue, S.P., Liang, D. Fei, R., Chen, X., Ye, S., Lui, Y., Yanwan, W., You, M. \& Guo, X. (1983) Subcellular site of antispermatogenic effect of gossypol and its possible molecular mechanism of action. Scien. Sin. 26, 614-633.

Received 18 April 1988 